\title{
Correspondence
}

\section{New method of assessing visual acuity}

SIR, In the article 'New method of assessing visual acuity with pictures' by Hazel Kay' no mention is made of the useful picture test described by Henry F. Allen. ${ }^{2}$ The set of pictures designed by Allen for testing the visual acuity of preschool children meets the objectives for an accurate test set forth by Mrs Kay, namely, one that is 'easily understood by 2-3 year old children, practicable for both examiner and child, and which is graded according to the Snellen's system.'

Dr Allen's picture test has been widely used by ophthalmologists and orthoptists in the United States and probably elsewhere during the past 25 years. It is readily available from ophthalmic equipment companies in the United States. Jules Stein Eye Institute,

LEONARD APT Department of Ophthalmology,

School of Medicine,

University of California, Los Angeles, USA

\section{References}

$1 \mathrm{Kay} \mathrm{H}$. New Method of assessing visual acuity with pictures. Br J Ophthalmol 1983; 67: 131-3.

2 Allen HF. A new picture series for preschool vision testing. Am J Ophthalmol 1957; 44: 38-41.

SIR, At the time of writing my article I was not familiar with the vision test that Dr Apt refers to in his letter. As far as I know the test is not used or even available in this country, and it was not referred to in any of the literature that I had access to during my research. However, I have since obtained a copy of Dr Allen's article and would like to make the following points.

(1) Dr Allen makes no mention of the test being easily understood by children under the age of 3. (2) I believe that Dr Allen's test consists of too few pictures to maintain a small child's attention and interest for the required length of time. I understand that the same 8 pictures are shown repeatedly at increasing distances from the child, which introduces a risk of the child remembering them or becoming bored. (3) Altering the fixation distance instead of the picture size involves changes in the accommodative state of the eye which can affect the resultant acuity. (4) Comparability with Snellen's letters seems unlikely, since although Dr Allen recognises the importance of pictures being constructed in the same way, with constant line width, ('fine lines below the threshold angle disappear entirely. Thick lines appear as black blobs ... .) his pictures are clearly not constructed on this basis. The results of his survey comparing the accuracy of his test with Snellen's acuity are unimpressive. He cites only 4 cases, in all of which the vision of the amblyopic eye is shown to be considerably better when tested with his pictures.

I cannot accept, therefore, Dr Apt's claim that Dr Allen's pictures meet the criteria for an accurate picture visual acuity test as stated in my article and as fulfilled by my own test. However, as I have limited knowledge of current use of
Dr Allen's test, I would welcome correspondence from $\mathrm{Dr}$ Apt or anyone else who has details of more recent research into its use and effectiveness. 32 Zetland Avenue North,

H. KAY Bolton BL3 3QT.

\section{Book reviews}

Documenta Ophthalmologica Proceedings Series 32. Strabismus Symposium, Amsterdam 1981. Eds. A. Th. M. van Balen and W. A. Houtman. Pp. 284. Dfl.140.00. W. Junk: The Hague. 1982.

The president (Professor Kurt Cuppers) reminded his audience that the original title of the Strabismological Symposia held in Europe was the CESSD (Concilium Europaeum Strabismi Studio Deditum), which was founded in Paris in 1961 by Dr Thomas under the direction of Professor Jules François. Its task consisted in arranging regular meetings to discuss problems of strabismology and co-ordinating them and passing the results on to various national working parties.

From the beginning the CESSD was a European organisation, at first limited to Western Europe. However in 1964, thanks to the efforts of Thomas, whose contacts with the World Health Organisation created the possibility of the CESSD being joined by representatives of the so-called Iron Curtain countries in Eastern Europe, this was duly carried out. The CESSD has never been a strabismological society in the usual meaning but, as Professor Cuppers sees it, an all-European committee (or council) which has the task of creating contacts for material understanding and for endeavouring to achieve harmony. The fact that in addition symposia, with admission of nonmembers, have been organised by the respective national representatives does not in the view of Professor Cuppers change its fundamental structure.

The publication of this symposium includes all the papers that were given. Part 1 started first with those concerned with physiological problems such as fixation disparity, anomalous fusion, sensorial interactions in re-educated strabismic amblyopia, and binocularity in comitant esotropia and exotropia. It also included a report on the results of the Cuppers Faden operation in cases of alternating congenital convergent strabismus, the possibility of correct fusion-formation of adults, and the early onset of esotropia. There was also a new hypothesis on latent nystagmus and on the congenital squint syndrome, and the influence of progressive press-on prisms on changing squinting angles.

Part 2 was concerned with noncomitant squint, starting with basic motor mechanisms in paretic squint, primary overaction of the inferior oblique muscle, the treatment of noncomitant strabismus, Duane's retraction syndrome, and oculomotor imbalance in congenital ptosis.

The meeting finished with an excellent round-table discussion chaired by Dr Crone on the subject of 'Posterior fixation suture in noncomitent squint' with special reference to the Faden operation. The 7 participants were Drs De 
Decker, Deller, Fells, Frosini, Kaufman, Koornneef, and Pechereau, who all gave interesting answers (depening on their experience) to the various questions put to them.

This book is of considerable interest and of practical value.

T. KEITH LYLE

A Study Guide for Glaucoma. Ed. M. Bruce ShIeldS. Pp. 544. £44·75. Williams and Wilkins: London. 1982.

This book edited by Dr Shields has no fewer than 24 doctors as authors. Its 35 chapters are presented in 3 sections: the basic features of glaucoma, clinical forms of glaucoma, and the pharmacology and surgery for glaucoma.

Of a good academic standard and profusely referenced, the book is excellently illustrated with clear line drawings throughout. These drawings are particularly impressive because they can illustrate specific points very much better than the glossy photographs which one is accustomed to see in new textbooks. Every possible aspect of the subject has been adequately covered and one could almost call this an 'encyclopaedia' of glaucoma rather than just a 'study guide'.

The book can be highly recommended both for mature ophthalmologists and for those studying for higher examinations; its wealth of references is particularly useful. The editor, authors, and illustrator are all to be highly commended for this valuable addition to ophthalmology.

REDMOND J. H. SMITH

Medikamentöse Augentherapie. By PAUL U. FeCHNER and Klaus D. Teichmann. Pp. 270. DM 88. Ferdinand Enke Verlag: Stuttgart. 1982.

It is natural that a reviewer in this country should compare foreign textbooks with their British counterparts, and once in a while one comes across a book that is enviably superior in its field to anything produced in the English language. This handbook of ocular therapeutics is a prime example and is to be highly recommended.

The authors have provided a comprehensive survey of ocular diseases that require medical rather than surgical therapy, and the available forms of treatment are listed. Each condition is described briefly, and the pathogenesis and medical management are discussed and references quoted where appropriate. The book includes sections on the commonly used ophthalmic drugs together with their indications and side effects. Some of the drugs recommended are not generally known in Britain and several are homoeopathic. This serves to emphasise that there are still differences between the approach to eye disease in various European countries-something that English ophthalmologists should not ignore. For the practising ophthalmologist and the trainee this is a most useful book, and provided it is kept up to date it should be essential reading. An English translation would be very welcome.

T. J. FFYTCHE

Ophthalmic Photography. Ed. Johnny Justice, JR. Pp. 277. US\$31 75. Little, Brown: Boston. 1982.

Twenty-five chapters by various authors are compressed into this small volume under the editorship of Johnny
Justice Jr. Two contributions are from Japan and the remainder from the USA. Black-and-white illustrations are used throughout, which no doubt help to hold down the cost. The book attempts to give a complete account of all photographic methods relevant to the eye from simple routine anterior segment photography to advanced research techniques. Recent techniques, such as specular microscopy of the corneal endothelium and anterior segment angiography, are well described. The book fails to cover other advanced measurement techniques, such as photogrammetry of the optic disc and slit-image photographic measurement of the anterior chamber and lens. Without going into these rather esoteric techniques it would at least be useful to have chapters on the photographic recording of the optic disc in the management of glaucoma. It is possible that these techniques have been omitted because there are no contributions from European authors. Photokeratometry is mentioned only in the historical section, but perhaps deserves more attention, since it is now in routine use in measuring the cornea for contact lenses.

In spite of these reservations this is a book to be recommended to any ophthalmic photographer in training or to any ophthalmologist wishing to use photography for clinical or for research purposes. NICHOLAS PHELPS BROWN

\section{Problems in Ophthalmology. By Michael} GLASSPOOL. Pp. 141. £7.95. MTP Press: 1982.

This book is one of the 'Problems in Practice Series' of which there are 10 other subject titles and a series index volume. It is directed towards general practitioners, with a forward by the president of their Royal College. It achieves its aim clearly and is well laid out. The author has considerable experience in successfully putting over the complexities of terminology used by ophthalmologists to the GP and bringing the common sense approach to bear on the specialty.

There are 11 chapter headings, of which the first 2 are 'History' and 'Examination,' both of which if read and digested would give many readers more insight into ophthalmology. There is a clear and simple exposition of the mysteries of assessing visual acuity and the nomenclature. The importance of visual loss, requiring immediate referral, cannot be too highly stressed. The cover test is clearly described and illustrated.

The next chapter discusses the red eye, and the emphasis is on differentiating the various conditions that should be referred to specialists, with commendable stress on the dangers of inappropriate initial treatment. 'The external eye' is followed by 'The internal eye.' The illustrations are in general clear and excellent and, being mainly photographs, are realistic. The artist's painting of a retinal detachment is an exception to this, as are the drawings of cataract changes seen silhouetted against the red reflex.

The chapters on 'Sudden loss of vision' and 'Slow loss of vision' between them describe 10 of the most common diagnoses encountered in the outpatient department, and the only anxiety is that any GP keen enough to follow the otherwise excellent diagrams illustrating the evolution of the field changes in chronic glaucoma will be confused by the use of 'combined' charts. The outline of the blind spot for central-field-only charting is inappropriately included 